\title{
Value of screening for gonorrhoea in obstetrics and gynaecology
}

\author{
P. I. SILVERSTONE AND C. A. SNODGRASS \\ Department of Obstetrics and Gynaecology, \\ AND \\ A. S. WIGFIELD \\ Department of Venereology, Newcastle General Hospital, Newcastle upon Tyne
}

Since the late 1950 s there has been a steady increase in the incidence of gonoccocal infections throughout the world, which is in marked contrast to the fall which followed the introduction of penicillin. Although drug resistance has been adduced as a contributory factor in the resurgence of gonorrhoea, the total involvement in the world today is far in excess of any available pre-penicillin figures. The fact that gonorrhoea is sexually transmitted makes the present world epidemic a vivid reflection of changed sexual mores in an increasingly licentious society.

A figure of $150,000,000$ cases of gonorrhoea in the world today has been often quoted, but a more recent World Health Organization estimate suggests that there are some $16,000,000$ new cases annually (Guthe, 1972). The British Isles have not escaped this increase. Several authorities have suggested that there exists a large population of symptomless carriers and that failure to control the disease is related to this reservoir of undetected infection. No one, in fact, knows the size of this reservoir nor will they do so until a large cross-section of the female population is appropriately screened.

From time to time venereologists have advocated that screening for gonorrhoea should be undertaken and have drawn attention to their own results. Zwahr (1968) found fourteen cases in 1,701 smears; nine of these were found among 368 abortion cases and four among sixty patients who were admitted for what he calls 'adnexal processes'. Waters and Roulston (1969) found 207 cases of gonorrhoea in 3,375 obstetric patients and gynaecological outpatients, an incidence of 6 per cent. Cave, Bloomfield, Hurdle, Gordon, and Hammock, (1969) found 25 ( 5.5 per cent.) cases of gonorrhoea in 452 obstetric admissions and 47 (11.1 per cent.) cases in 423 patients in the gynaecological clinic. Kraus and Yen (1968) found that 5.73 per cent. of 1,309 antepartum patients harboured the gonococcus. On the other hand, Gaal, Rich and Hansman (1968) found no gonococci in 200 antenatal patients. Schofield (1969)

Received for publication May 81973 found 48 cases of post-pubertal gonorrhoea in women whose children were discovered to have gonococcal ophthalmia and he recommended the selection of cases for testing based on certain social characteristics. No small task, this, when it is understood these 48 cases were from 120,000 confinements over a period of 6 years.

'It is not known how high the graphs must climb before others besides venereologists join in the demand for routine screening of antenatal and gynaecological cases for gonorrhoea. On the other hand, there is no doubt that such a venture would be enormously expensive and involve a vast increase in the amount of work undertaken by public health laboratories and pathologists. Indeed, the majority of laboratories and pathologists could not cope with such a proposition before the government of the day could be persuaded to spend vast sums of money on capital projects, equipment, and salaries to cope with such demand. It would first have to be persuaded that the results were going to justify the means. It might well be argued that the male urethra remains the best culture medium for gonococci coming from female cases and that routine case-finding methods will have to suffice for many years to come' (Wigfield, 1971).

One of us has suggested (Wigfield, 1972) that this reservoir of untapped gonorrhoea may not be nearly so vast as has hitherto been supposed. Though it exists its membership continually changes. The incidence of gonorrhoea is more likely to relate to the impetuous promiscuity of otherwise healthy but sexually active young males coupled with the high infectivity of the gonococcus and the short incubation period.

Gynaecologists presented with the problem of vaginal discharge treat a small number of cases of gonorrhoea either by design or inadvertently when antibiotics are prescribed, and may possibly miss a few cases if the gonococcus is not specifically looked for. They also treat overt cases if admitted to their wards with acute salpingitis. The majority of cases of uncomplicated gonorrhoea will present at venereal 
diseases clinics where, for the most part and for many years, routine screening of 'unmarried mothers' has also been undertaken. In 4 years (1967-70), 81 such patients have been screened in Newcastle and six cases of gonorrhoea discovered (7.5 per cent.). Since the Abortion Act of 1967, it is evident that gynaecologists are increasingly faced with a new clientèle of possible carriers of the gonococcus. This has raised new questions in the screening programmes designed to detect gonococci and it might be argued that centres dealing with referrals for termination should endeavour to identify 'at risk' groups of patients with this disease in mind.

Apart from an apparent need to search for cases of gonorrhoea, one notes that there has recently been established a possible association between gonorrhoea and squamous carcinoma of the cervix uteri. Coppleson (1969) states that women with carcinoma of the cervix show a higher frequency of sexually transmissible disease than women without carcinoma. Two studies quoted in his review mention an increased incidence of gonorrhoea in women with squamous carcinoma of the cervix, whilst a further two studies quoted show a similar relationship with trichomonal vaginitis. There may be no causal relationship between squamous carcinoma of the cervix and previous cervical infection, the operative factor in both conditions being sexual activity. Way, Hennigan, and Wright (1968) noted that sexual activity and multiple sexual partners were dominant features of their group of 551 patients with preinvasive and invasive carcinoma of the cervix. The incidence of positive cervical smears in their group amongst patients married once was one in 99, amongst those married twice or more it was one in 22.

At the Newcastle General Hospital, from February, 1971 , routine screening for gonorrhoea had been concentrated on all unmarried patients booking at the antenatal clinics together with those patients referred for termination of pregnancy. The screening programme for syphilis had involved these patients as well as all other antenatal patients since 1943. The method used to detect gonorrhoea comprised urethral and cervical swabs sent in Stuart's transport medium to the Public Health Laboratory within the hospital, together with referral of the patient to the venereology department in the light of positive or suspicious findings. This method proved a heavy burden on the laboratory services, yet no positive cultures were found out of 673 patients screened routinely in the first 8 months of 1971. During this time there were three patients with clinical gonorrhoea who did not come within the routine screening programme. Two were infants with ophthalmia neonatorum; the third was the mother of one of these infants. She had attended the antenatal clinic and was asymptomatic. Not being considered at risk, she was not screened.

To test the value of increasing the scope of the routine screening programme in the hospital, a survey was conducted for three months in late 1971 .

\section{Material and methods}

\section{PATIENTS}

The survey was conducted jointly by the Departments of Bacteriology, Obstetrics and Gynaecology, and Venereology at the Newcastle General Hospital from midSeptember to mid-December, 1971. The following groups of patients were screened:

(1) All women referred for termination of pregnancy (Problem Pregnancy Clinic);

(2) All women attending the antenatal consultation clinic of one of us (C. A. Snodgrass) for the first time, together with the following groups of patients selected from other antenatal clinics:

(a) Those under 20 years of age;

(b) Those described as having conceived extramaritally;

(c) Those with vaginal discharge;

(3) All women under 40 years of age attending the gynaecological clinic of one of us (C. A. Snodgrass) for the first time.

(4) All women admitted with acute gynaecological symptoms.

\section{METHODS}

Each patient was examined for syphilis by a serological test (VDRL) and for gonorrhoea, trichomoniasis, moniliasis, and abnormal cervical cytology by microscopy. Pelvic examination was made with a sterile Cusco's speculum without lubricant and a sample of the posterior fornix pool taken. This was mixed with a drop of saline and examined by direct microscopy for Trichomonas vaginalis. A cervical smear was taken with an Ayres spatula and, after the cervix had been mopped with sterile cotton-wool, an intracervical swab using plain sterile cotton-wool was taken. This was smeared on to a clean, dry glass slide and left to dry. These slides were submitted to the Department of Venereology for Gramstaining and reporting. The VDRL was carried out on venous blood submitted to the Public Health Laboratory.

When clinical gonorrhoea was suspected the patient was referred to the Department of Venereology. In cases of patients admitted with acute gynaecological symptoms, intracervical swabs were sent in Stuart's medium to the Public Health Laboratory for diagnosis by culture and slides were prepared for diagnosis by microscopy.

It needs to be explained that urethral smears were not taken since the venereal disease clinic figures show that, whereas reliance on urethral and cervical smears without cultures would result in the loss of 24.8 per cent of cases (62 out of 250 consecutive female gonorrhoea cases being diagnosed on culture alone), reliance on cervical smears alone would result in the loss of $27 \cdot 6$ per cent. (69/250). To include urethral smears increases the 'yield' by $2 \cdot 8$ per cent. only. 
Of greater consequence is the omission of cultures in the routine screening. These were not undertaken as in the previous survey so that the cost/benefit ratio of both methods could be assessed with special reference to the bacteriology laboratory. In the light of the results of this survey it would seem that the omission of cultures was no serious lapse, but clearly any screening for gonorrhoea that became a routine part of hospital practice would necessarily include the examination of both smears and cultures from the urethra and cervix, and even, as many would insist, from the rectum. In a series of 116 consecutive female patients with gonorrhoea in the venereal disease clinic ten ( 8.6 per cent.) were diagnosed on urethral smear or culture when cervical smears and cultures were both negative.

\section{Results}

Full information was obtained concerning 370 patients from four sources.

Table I shows the distribution of these patients by marital status and age, and Table II by marital status and source.

TABLE I Marital status and age of patients screened

\begin{tabular}{|c|c|c|c|c|c|}
\hline \multirow{2}{*}{$\begin{array}{l}\text { Marital } \\
\text { status }\end{array}$} & \multicolumn{5}{|l|}{ Age (yrs) } \\
\hline & Under 20 & $20-24$ & $25-29$ & $\begin{array}{l}30 \text { and } \\
\text { over }\end{array}$ & Total \\
\hline Married & 27 & 59 & 52 & 77 & 215 \\
\hline Single & 75 & 43 & 17 & 20 & 155 \\
\hline Total & 102 & 102 & 69 & 97 & 370 \\
\hline
\end{tabular}

TABLE II Marital status and source of patients screened

\begin{tabular}{|c|c|c|c|}
\hline \multirow{2}{*}{ Source } & \multicolumn{3}{|c|}{ Marital status } \\
\hline & Married & Single & Total \\
\hline Problem pregnancy clinic & 52 & 66 & 118 \\
\hline Antenatal clinic & 123 & 70 & 193 \\
\hline Gynaecological clinic & 28 & 13 & 41 \\
\hline Acute admissions & 12 & 6 & 18 \\
\hline Total & 215 & 155 & 370 \\
\hline
\end{tabular}

The age distribution was such that, unlike the patients at the venereal disease clinic, most of the women were married; the majority screened were pregnant at the time of examination.

Table III gives details of the results of screening these patients. Rather unexpectedly there was no overlap in the microbiological findings. Eight patients were referred for further investigation on the basis of the first examination, Gram-negative diplococci being found on their cervical slides. One of these patients, seen in the gynaecological clinic and com-
TABLE II T Total results from the four sources (370 patients screened)

\begin{tabular}{|c|c|}
\hline $\begin{array}{l}\text { No. of patients referred with Gram-negative organisms } \\
\text { including ONE positive and SEVEN negative for } \\
N \text {. gonorrhoeae }\end{array}$ & 8 \\
\hline No. of patients with positive VDRL test & 1 \\
\hline No. positive for Trichomonas vaginalis & 22 \\
\hline No. positive for monilia & 34 \\
\hline $\begin{array}{l}\text { No. of patients with positive cervical cytology, including } \\
\text { ONE with non-gonococcal Gram-negative organisms }\end{array}$ & 4 \\
\hline Total no. of positive findings & $69^{\mathrm{a}}$ \\
\hline No. of patients without any findings and not referred & 302 \\
\hline
\end{tabular}

plaining of a menstrual irregularity, was found to have $N$. gonorrhoeae on further investigation. She also had signs suggestive of gonorrhoea when seen at the clinic. The other patients had Gram-negative organisms judged to be of doubtful significance by the Department of Venereology and cultures for the gonococcus were negative. Of two further patients referred for further investigation, one (referred from the antenatal clinic) had a positive VDRL test, but was already known to the Department of Venereology; the other had trichomonal vaginitis.

Trichomonal infestations were diagnosed in 22 patients either on direct microscopy or by Papanicolaou smear. Eight of these had been referred for termination of pregnancy and had attended the antenatal clinics, two had attended the gynaecological clinic, and one had been seen in the acute admission ward. Of these 22 patients only four were married; three married and sixteen single patients were pregnant at the time of examination.

A monilial infection was diagnosed in 34 patients both on dry smear and cervical cytology. Thirteen had been referred for termination of pregnancy, nineteen for antenatal care, one for emergency admission, and one for a gynaecological opinion.

The cytologist found abnormal cervical cytology in four patients. One smear was Grade IV, one Grade III, and two Grades II-III. The patient with the Grade IV smear was married and had been referred for termination of her fourth pregnancy. The patient with the Grade III smear was referred for a gynaecological opinion following a complaint of irregular periods. Both of these patients had pre-invasive squamous carcinoma of the cervix and were eventually treated by abdominal hysterectomy. The two patients with Grade II-III smears were unmarried and referred for termination of pregnancy. These smears reverted to normal after termination had been performed. One of these patients was among the 
group found to have Gram-negative diplococci of no significance on a cervical slide taken at the initial examination.

No abnormality was found in $\mathbf{3 0 2}$ of the patients screened.

\section{Discussion}

The discovery of one case of gonorrhoea in 370 patients screened would appear to be a small return for an excessive effort. Using all techniques, that is smears and cultures from the urethra and cervix in all patients screened, the estimated return for the units in which this survey was conducted would be two cases. Such an exercise is not justified on a cost/benefit basis. Moreover, previous experience suggests that screening on an 'at risk' selection basis is of dubious value.

Hughes and Davies (1971) screened 1,000 new gynaecological patients at random and found that the only three with gonorrhoea would have been screened for this infection as a matter of routine, by virtue of the reason for their referral. Rees and Hamlett (1972) and Cassie and Stevenson (1973) screened antenatal patients in Liverpool and Glasgow respectively; both demonstrated that routine screening of these patients was of doubtful value in detecting occult gonorrhoea, and concluded that it was unnecessary.

Innocently infected wives and regular girl-friends are on the receiving end of male promiscuity and constitute no public health risk, although they provide the bulk of female gonorrhoea patients seen in the venereal disease clinics. Promiscuous females, or those thought to be so, should be screened, since the primary purpose of screening is to stem the tide rather than to treat the cases.

Since this survey it has been decided that, at the Newcastle General Hospital, screening for gonorrhoea should continue only on a limited basis using clinical judgement on individual patients to detect those who may have this disease. The usefulness of this approach will be continuously reviewed. The VDRL will still be carried out on all pregnant patients.

\section{Summary}

The value of screening for gonorrhoea in obstetrics and gynaecology was investigated in a group of patients over a period of 3 months by Gram-stained cervical smears. VDRL tests were also undertaken and further smears were examined for Trichomonas vaginalis, moniliasis, and cervical cytology. Infestation with Trichomonas vaginalis was commoner in unmarried patients and those who had conceived extramaritally. Monilial infection was more common in pregnancy. Four patients had abnormal cervical cytology; two were related to pre-invasive squamous carcinoma and the other two were normal when repeated. Only one patient was found to have gonorrhoea and this patient had clinical signs suggestive of the disease. The one patient with a positive VDRL test was already known to the Department of Venereology.

We wish to thank the staff of the Department of Obstetrics and Gynaecology of Newcastle General Hospital for their co-operation, Mr. D. Minto and the staff of the Venereology Department for their technical assistance, the nursing staff of the clinics involved, and Mrs. J. A. Fatkin for secretarial assistance. We also wish to thank Dr. J. B. Selkon, consultant bacteriologist, for his advice and Dr. B. J. Murray for collating the results.

\section{References}

Cassie, R., and Stevenson, A. (1973) f. Obstet. Gynaec. Brit. Cwlth, 80, 48

Cave, V. G., Bloomfield, R. D., Hurdle, E. S., Gordon, W. E., and Hammock, D. (1969) f. Amer. med. Ass., 210, 309

Coppleson, M. (1969) Brit. F. Hosp. Med., 2, 961

GaAl, R., Rich, R., and Hansman, D. (1968) Med. F. Aust., 1, 634

Guthe, T. (1972) Postgrad. med. F., 48, Suppl. 1 (Jan.), p. 7

Hughes, W. M., and Davies, J. M. (1971) Brit. med. F., 4,424

KraUs, G. W., and YeN, S. S. C. (1968) Obstet. and Gynec., 31, 258

ReEs, D. A., and Hamlett, J. D. (1972) f. Obstet. Gynaec. Brit. Cwlth, 79, 344

SCHOFIELD, C. B. S. (1969) Lancet, 2, 1182

WATERS, J. R., and Roulston, T. M. (1969) Amer. F. Obstet. Gynec., 103, 532

Way, S., HenNigan, M., and Wright, V. C. (1968) f. Obstet. Gynaec. Brit. Cwlth, 75, 593

WIGFIELD, A. S. (1971) Gaz. sanit. (English ed.), 20, 111 - (1972) Brit. med. f., 4, 672

ZWAHR, C. (1968) Zbl. Gynäk., 90, 1192

Valeur de la recherche systématique de la gonococcie en obstétrique et en gynécologie

La recherche systématique de la gonococcie en obstétrique et en gynécologie, par la coloration de Gram sur des prélèvements cervicaux, a été évaluée sur un groupe de malades pendant une période de 3 mois. On pratiqua en outre un VDRL, on rechercha sur les étalements le Trichomonas vaginalis, une moniliase et on étudia la cytologie cervicale. L'infestation par Trichomonas vaginalis fut plus fréquente chez les malades non mariées et chez les mères célibataires. L'infection moniliale fut plus fréquente lors de la grossesse. La cytologie cervicale fut anormale chez 4 malades; dans 2 cas il s'agissait d'un épithélioma pavimenteux au stade de pré-invasion. Dans les 2 autres cas, la cytologie fut normale au deuxième examen. On ne trouva qu'un cas de gonococcie et la malade avait des signes cliniques évoquant la maladie. La seule malade qui avait un VDRL positif était déjà connue au Département de Vénéréologie. 